The Financial Crisis 

Ted Azarmi • Wolfgang Amann

Editors

\section{The Financial Crisis}

Implications for Research and Teaching

昞 Springer 


\section{Editors}

Ted Azarmi

Heilbronn University and the

University of Tuebingen

Heilbronn and Tuebingen, Germany
Wolfgang Amann

SBUM/EMBA

HEC Paris School of Management in Qatar

Doha, Qatar

ISBN 978-3-319-20587-8

ISBN 978-3-319-20588-5 (eBook)

DOI 10.1007/978-3-319-20588-5

Library of Congress Control Number: 2016942537

(C) Springer International Publishing Switzerland 2016

This work is subject to copyright. All rights are reserved by the Publisher, whether the whole or part of the material is concerned, specifically the rights of translation, reprinting, reuse of illustrations, recitation, broadcasting, reproduction on microfilms or in any other physical way, and transmission or information storage and retrieval, electronic adaptation, computer software, or by similar or dissimilar methodology now known or hereafter developed.

The use of general descriptive names, registered names, trademarks, service marks, etc. in this publication does not imply, even in the absence of a specific statement, that such names are exempt from the relevant protective laws and regulations and therefore free for general use.

The publisher, the authors and the editors are safe to assume that the advice and information in this book are believed to be true and accurate at the date of publication. Neither the publisher nor the authors or the editors give a warranty, express or implied, with respect to the material contained herein or for any errors or omissions that may have been made.

Printed on acid-free paper

This Springer imprint is published by Springer Nature

The registered company is Springer International Publishing AG Switzerland 


\section{Preface}

This book is partially based on the proceedings of a finance conference titled "Teaching Finance in Turbulent Times," which Mathias Moersch and I organized at Heilbronn University in Germany in September 2013. Included here are a number of academic papers accepted for publication based on the subject matter of that conference.

Wolfgang Amann and I believed writing several additional chapters in this book would help students learn about financial crisis. These chapters allowed us to retrace the goals of the conference in written form.

Our first goal is to prepare students to deal with financial crisis in their future careers. At the conference, we arranged presentations from a high ranking financial regulator, the dean of a pioneering German MBA school, and the director of one of the best German financial executive education programs.

Our second goal is to highlight financial perspectives outside the standard neoclassical framework of commonplace ideas, such as sustainable finance and behavioral finance.

Our third goal is to present a holistic approach to financial education, which includes new research frontiers from both senior and assistant professors. In the conference, we asked presenters to discuss how they would use their research in their teaching in order to ensure their discussions were focused on the pedagogical implications of that research.

Our fourth objective is to focus on international perspectives in finance, not the perspective of international finance in academics, because international finance is an established field of study that focuses on market structure, trading, and arbitrage in foreign exchange markets, parity conditions, hedging transaction, translation and operating risk, cross-border valuations, international corporate governance, swaps, and a few related topics. By a focus in perspectives in international finance, we mean finance as practiced and taught in Germany, Japan, Russia, Ukraine, Israel, the Arab World, EU, etc., in contrast to the standard, US-based body of financial knowledge and practice. 
Finally, we are interested in introducing finance as a field of study to business students about to choose a major. In particular, Chap. 2 of this book focuses on the major achievements and tools of this field, its failures, and shortcomings. In this way, we hope to motivate students considering finance as a field of study to actually pursue it.

One of the challenges to achieving our goals during the Heilbronn finance conference was to facilitate the active participation of undergraduate and graduate students, in addition to the usual participation of Professors and $\mathrm{PhD}$ students. To do this, we encouraged students to participate in the conference in every finance class and particularly in the introductory financial management course. In order to translate the high level of awareness about the Heilbronn conference into actual student attendance and participation, we relied on a conference blog site where students work and essays related to the conference could be posted. To read the blog, visit: http://www.azarmi.org/forum/index.php/board,355.0.html.

One factor attracting student attention was that the blog was made public allowing for a wide readership, including one student blog on finance that received 4181 views.

After working for hours and answering several questions by students, one prominent senior finance professor volunteered to spend time with undergraduates to chat informally about finance. Some 12 students took him up on the offer, and their impromptu meeting was still in progress over an hour after the day's conference ended. In effect, we captured an audience passionate about finance as a field of study, all at a time when the field suffered a figurative black eye from the many recent financial scandals and the crisis. Indeed, it was a turbulent time for finance!

Our business program at Heilbronn strongly emphasizes eastern European studies, intercultural studies, and the Arab world. This includes advanced language and business culture courses in Arabic, Russian, Spanish, and French. Students may choose to take all their required business courses either in English or in German for the entire period of their bachelor studies. Within a single semester, they have the opportunity to participate in two sessions of the same introductory finance course, one in German and the other in American English. Our average finance student is fluent in three languages. So in addition to course work in English and German, a typical finance graduate is required to take several language and culture courses in Arabic, Spanish, or French.

The finance program has begun to standardize and assimilate content from our English finance courses with their sister courses taught in German. Despite this effort, we realize that German finance differs in certain significant aspects from US finance, requiring a chapter or two of additional course discussion elucidating those differences. For example, the accounting information provided by German HGB and the European accounting differs from US GAAP. There are also fundamental differences in how German firms are financed in practice.

We also experienced setbacks in achieving some of the Heilbronn finance conference's goals. In particular, we only partially covered the implications of the financial crisis. However, we are optimistic that with sufficient effort and 
persistence, our goals can be achieved. We hope that building upon our modest success, this book-let's call it volume I-will enable us to convince our stakeholders to participate in the production of a second volume that will elaborate the various issues that this volume cannot encompass.

Heilbronn, Germany

Ted Azarmi 



\section{Contents}

Introduction: Finance and the Financial Crisis . . . . . . . . . . . . . 1

Ted Azarmi

Corporate Governance and Restructuring Through Spin-Offs:

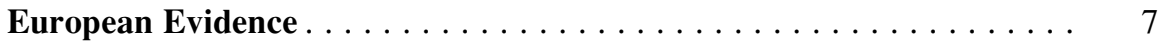

Dmitri Boreiko and Maurizio Murgia

Alternative Specifications of Bank Lending in France and Germany:

Theory, Evidence, and Policy Implications . . . . . . . . . . . . . . . . . 49

Robert E. Krainer

Toward Banking Union in Europe: An Interim Assessment . . . . . . . . 89

Christian Schmidt

A World Without Money Needs No Banks and No Rating . . . . . . . . . 115

Ottmar Schneck

Put-Call Parity Violations Under Limited Arbitrage: A Case Study and a Simulation Tool for Detecting Financial Irregularity . . . . . . . . 125 Ted Azarmi and Paul Borochin

Enabling Holistic Finance Education in Turbulent Times . . . . . . . . . . 137

Wolfgang Amann

Actual Problems of Finance Teaching in Ukraine in the Post-Crisis

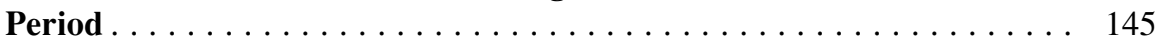

Serhiy Lyeonov and Olga Liuta

Executive Compensation and Risk Taking: The Impact of Systemic

Crises .

Alon Raviv and Elif Sisli-Ciamarra 
Measuring the Success of Executive Education: Comprehensively

Depicting Holistic Finance Education . . . . . . . . . . . . . . . . . 165

Wolfgang Amann

Conclusion: Emerging Insights on Teaching Finance in Turbulent

Times...................................... 173

Wolfgang Amann 


\section{About the Editors}
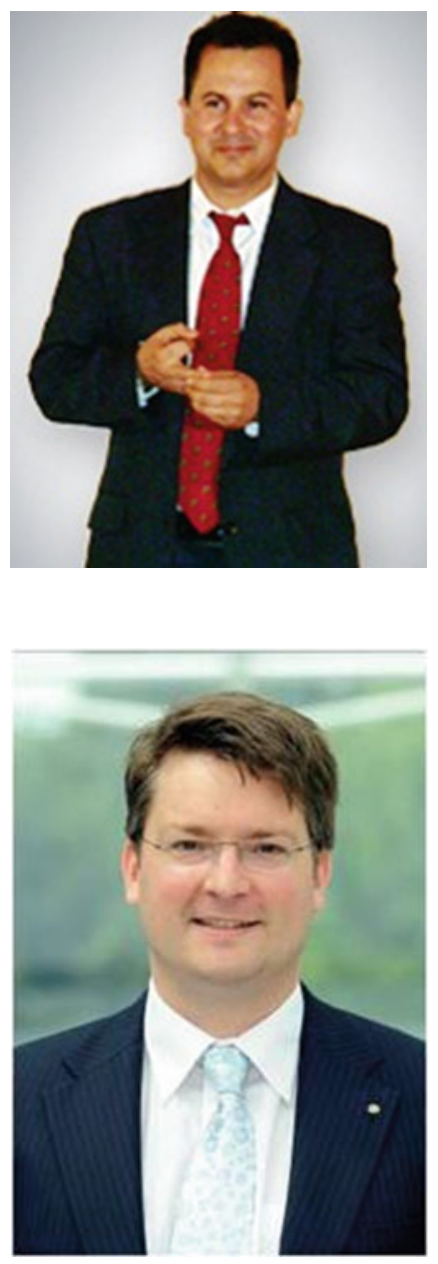

Prof. Ted Azarmi, PhD, trains doctoral students in finance at the University of Tuebingen. He is also a finance professor at Heilbronn University. He has 25 years of experience as a business professor in USA, Japan, and Germany. Ted Azarmi has several teaching excellence awards from USA for which he received newspaper coverage in Los Angeles area.

Prof. Dr. Wolfgang Amann has been designing and delivering executive education seminars for more than 17 years. He now serves as academic director and professor of strategy and leadership at HEC Paris in Qatar. Next to his doctorate in international strategic management from the University of St. Gallen, he also graduated from the major faculty development programs worldwide, such as Harvard University's MLE, IMD's ITP, IESE's IFP, and EFMD IDP. He published 15 books for executives and compiled more than 100 case studies for his executive education seminars. He won several global and pan-European prizes for his research as well as teaching efforts and was awarded several honorary professorships. 